\title{
The Prevalence of Migraine in Different Parts of Iran: Review of the Current Evidence
}

\author{
Omid Sadeghi ${ }^{1}$; Morteza Nasiri ${ }^{2, *}$; Saed Ghasem Saiedi ${ }^{2}$ \\ ${ }^{1}$ Student Research Committee, Department of Nutrition, School of Nutrition and Food Sciences, Isfahan University of Medical Sciences, Isfahan, IR Iran \\ ${ }^{2}$ Student Research Committee, Department of Nursing, Nursing and Midwifery School, Ahvaz Jundishapur University of Medical Sciences, Ahvaz, IR Iran \\ ${ }^{*}$ Corresponding author: Morteza Nasiri, Student Research Committee, Department of Nursing, Nursing and Midwifery School, Ahvaz Jundishapur University of Medical Sciences, \\ Ahvaz, IR Iran. Tel: +98-9171745485, Fax: +98-7735325292, E-mail: mortezanasiri.or87@yahoo.com
}

Received: February 3, 2015; Revised: April 7, 2015; Accepted: April 19, 2015

\begin{abstract}
Context: Migraine is a type of primary headache that affects $10 \%$ to $20 \%$ of people worldwide. Recent studies have reported different prevalences of migraine in Iran. Hence, this study aimed to review current evidences related to the prevalence of migraine in different parts of Iran.

Evidence Acquisition: A literature search was done for related articles published between 1998 and 2014 on PubMed, Science Direct, Embase, Web of Science, Medline, Scopus for English language articles, and on Iran Medex, Magiran and SID (Scientific Information Database) for Persian (Farsi) language articles by the following keywords: "migraine", "headache", "prevalence" and "Iran".

Results: In most evaluated studies, migraine had a higher prevalence in middle-age individuals and females. The prevalence of migraine in adults varies from $7.14 \%$ to $18.11 \%$, and the maximum and minimum prevalence was reported from Tehran and Zahedan, respectively. In children and adolescences, the prevalence varies from 1.7\% to 12.3\%, and the lowest and highest prevalence were found in Shiraz and Yazd, respectively.

Conclusions: Based on the current findings, the prevalence of migraine in evaluated studies was high. Therefore, it is recommended for public health authorities to detect the reasons for the high prevalence of this disease and set appropriate strategies to prevent this disorder.
\end{abstract}

Keywords: Migraine Disorders; Headache; Prevalence; Iran

\section{Context}

Migraine is a common chronic, disabling, debilitating and progressive intermittent neurovascular headache disorder $(1,2)$. This disorder is characterized by severe recurrent headache, nausea, vomiting, sensitivity to light and sound, neck pain and muscle tension, as well as photophobia and phonophobia $(3,4)$. Migraine headaches are one-sided throbbing that usually last between four to 72 hours $(5,6)$. Based on the International Headache Society (IHS) criteria, there are two major classes of migraine: Migraine with Aura (MA) and Migraine without Aura (MOA) (7). These two subtypes have the same symptoms, yet $25 \%$ of patients with migraine perceive an aura, which is a transient disturbance in visual, sensory, language, or motor function and define it as a signal of headache occurrence (8).

The etiology of migraine is unknown, but it has been shown that genetic and environmental factors including Methylenetetrahydrofolate Reductase (MTHFR) mutation (9), inflammatory factors (10), obesity and inappropriate dietary patterns (11) are involved in the etiology of this disease.

Recent studies have indicated that one in every four American adults has frequent or severe headaches in- cluding migraines (4). The precise prevalence of migraine is unknown and based on previous reports, the prevalence of this disorder is different around the world. One large epidemiological study in the United States reported the prevalence of this disorder as $13.2 \%$, $8.6 \%$ and $17.5 \%$ for the total population, males and females, respectively (12). In addition, evidences have shown a prevalence of $14.7 \%$ in European adults and 3\% and $10 \%$ in Asian males and females, respectively (13, 14). In Iran, as an Asian country, different prevalence of migraine has been reported. Epidemiological studies reported the highest prevalence (18.11\%) of migraine in adults residing in Tehran (15) and the lowest prevalence $(1.7 \%)$ was reported for primary-school children in Shiraz (16). Unfortunately, no comprehensive study has been conducted to determine the prevalence of migraine in different parts of Iran, and most studies have been done in one city or area. Therefore, due to the above-mentioned reasons and since no study has reviewed published studies about the prevalence of migraine in Iran, we aimed to review published studies about the prevalence of migraine in different regions of Iran in order to help public health authorities under-

Copyright (C) 2015, Ahvaz Jundishapur University of Medical Sciences. This is an open-access article distributed under the terms of the Creative Commons Attribution-NonCommercial 4.0 International License (http://creativecommons.org/licenses/by-nc/4.0/) which permits copy and redistribute the material just in noncommercial usages, provided the original work is properly cited. 
stand the magnitude of the problem, and consequently improve diagnostic and therapeutic methods to reduce this burden.

\section{Evidence Acquisition}

In this review article, we performed an electronic search on articles published from $1^{\text {st }}$ of January 1998 to $30^{\text {th }}$ of December 2014, on PubMed, Science Direct, Embase, Web of Science, Medline, Scopus for English language articles, and on Iran Medex, Magiran and Scientific Information Database (SID) for Persian (Farsi) language articles, using the following keywords as Medical Subject Headings (MeSH): "Migraine Disorders", "headache", "prevalence" and "Iran". The references of retrieved items were also searched to identify additional items about this topic. In addition, reference lists of journal papers were searched by hand for relevant papers. We included articles that examined the prevalence of migraine in different regions of Iran in patients aged $\geq 6$ years with a standard method for diagnosis of migraine and original data about the prevalence of migraine. We excluded studies that focused on headache; tension-type headache and chronic pain. Moreover, we excluded letter and review articles.

The relevance of articles was determined by the assessment of titles, abstracts and full text of papers. In total, we found 58 items (including duplication). After careful reading of titles, abstracts, and full texts (when available), 52 articles were initially selected, yet after further reading, 45 studies that met the eligibility criteria were included. We excluded 29 of these 45 articles due to evaluation of headache, tension-type headache and chronic pain (25 items), invalid method for diagnosis of migraine (three items) and being a letter (one item). Therefore, 16 studies were finally included in this review. The information gathered from the articles was summarized in tables based on a fixed protocol as follows: leading author, year of publication, assessed city, sample size, mean or range of age, the number of migraine patients and their prevalence rate in the total population and both genders. In addition, the prevalence of migraine in each region was visualized by figures.

\section{Results}

Among the 16 evaluated studies, 10 studies were done on adults $(15,17-25)$ and six studies were conducted on children and adolescences (16, 26-30). Of the 10 reviewed studies on adults, two studies were conducted in Zahedan $(22,23)$ and one study was conducted for each of the following cities, Tehran (15), Isfahan (19), Bandar Abbas (20), Shiraz (16), Kerman (18), Zanjan (21), Ardabil (24) and Ilam (25). Of the six reviewed studies on children and adolescences, two studies were conducted in Shiraz $(16,26)$ while in Yazd (27), Brijand (28), Rasht (29) and Shahrkord (30) only one study was done. Sample sizes of studies ranged from 210 to 3655 and age of the samples ranged from 6 to 100 years. Most studies (15-25, 27-29) were conducted on both genders while two studies (26, 30 ) were performed only on females. Among reviewed studies, eight studies $(15-17,24,25,28-30)$ were published in the English language and eight studies (18, 21, 22, 24, 25, 28-30) were published in the Persian (Farsi) language. In all suites, IHS criteria were used for diagnosis of migraine. The information obtained from these studies is presented in Tables 1 and 2 . In addition, the prevalence of migraine in each region is indicated in Figures 1 and 2.

\begin{tabular}{|c|c|c|c|c|c|c|c|c|c|}
\hline Reference & $\begin{array}{c}\text { Year of } \\
\text { Publication }\end{array}$ & City & $\begin{array}{l}\text { Age Range, } y \\
\text { or Mean } \pm S D\end{array}$ & Total & Migraine $^{\mathrm{a}}$ & $\begin{array}{l}\text { Total } \\
\text { Males }\end{array}$ & $\begin{array}{c}\text { Males' }^{\prime} \\
\text { Migraine }^{a}\end{array}$ & $\begin{array}{c}\text { Total } \\
\text { Females }\end{array}$ & $\begin{array}{c}\text { Females' } \\
\text { Migraine }^{\mathrm{a}}\end{array}$ \\
\hline Shahbeigi et al. (15) & 2013 & Tehran & $10-95$ & 3655 & $662(18.11)$ & 1206 & $127(10.6)$ & 2449 & $535(22)$ \\
\hline Ghorbani et al. (19) & 2013 & Isfahan & $18-31$ & 480 & $68(14.2)$ & 258 & $27(10.5)$ & 222 & $41(18.5)$ \\
\hline $\begin{array}{l}\text { Yazdanparast and } \\
\text { Abrishamizadeh (20) }\end{array}$ & 2013 & Bandar Abbas & $21.28 \pm 2.78$ & 350 & $57(16.3)$ & 114 & $29(25.4)$ & 236 & $28(11.9)$ \\
\hline $\begin{array}{l}\text { Ayatollahi and } \\
\text { Khosravi (16) }\end{array}$ & 2006 & Shiraz & $25-50$ & 1023 & $115(11.2)$ & 310 & $18(5.8)$ & 713 & $97(13.6)$ \\
\hline $\begin{array}{l}\text { Bahrampour and } \\
\text { Mobashe (18) }\end{array}$ & 1998 & Kerman & $10-100$ & 1029 & $107(10.4)$ & 556 & $40(7.2)$ & 473 & $67(14.2)$ \\
\hline Yusefy (21) & 1999 & Zanjan & $17-45$ & 554 & $61(11.01)$ & 350 & $33(9.4)$ & 204 & $28(13.7)$ \\
\hline Shahraki et al.(22) & 2006 & Zahedan & $35.7 \pm 6.55$ & 1539 & $149(9.7)$ & 616 & $41(6.6)$ & 923 & $110(11.9)$ \\
\hline Shahrakai et al. (23) & 2011 & Zahedan & $20-30$ & 210 & $15(7.14)$ & 94 & $5(5.3)$ & 116 & $10(8.7)$ \\
\hline Hashemilar et al.(24) & 2004 & Ardabil & 20.78 & 631 & $46(7.3)$ & 147 & $5(3.4)$ & 484 & $41(8.4)$ \\
\hline Modara (25) & 2008 & Ilam & $21.5 \pm 2.2$ & 309 & $25(8.1)$ & 69 & $6(8.9)$ & 213 & $19(8.9)$ \\
\hline
\end{tabular}

a Values are presented as No (\%). 
Sadeghi $O$ et al.

\begin{tabular}{|c|c|c|c|c|c|c|c|c|c|}
\hline Reference & $\begin{array}{c}\text { Year of } \\
\text { publication }\end{array}$ & City & $\begin{array}{c}\text { Age range, } y \text { or } \\
\text { Mean } \pm S D\end{array}$ & Total & Migraine $^{\mathrm{a}}$ & $\begin{array}{l}\text { Total } \\
\text { Males }\end{array}$ & $\begin{array}{c}\text { Males' } \\
\text { Migraine }^{a}\end{array}$ & $\begin{array}{c}\text { Total } \\
\text { Females }\end{array}$ & $\begin{array}{c}\text { Females' } \\
\text { Migraine }^{\mathrm{a}}\end{array}$ \\
\hline $\begin{array}{l}\text { Ayatollahi and } \\
\text { Khosravi (16) }\end{array}$ & 2006 & Shiraz & $6-13$ & 2226 & $38(1.7)$ & 1171 & $16(1.4)$ & 1055 & $22(2.1)$ \\
\hline $\begin{array}{l}\text { Fallahzadeh and } \\
\text { Alihaydari (27) }\end{array}$ & 2011 & Yazd & $12-14$ & 930 & $114(12.3)$ & 469 & $73(15.61)$ & 461 & $41(8.9)$ \\
\hline Ayatollahi et al. (26) & 2002 & Shiraz & $11-18$ & & & & & 1868 & $114(6.1)$ \\
\hline Khazaie et al. (28) & 2011 & Birjand & $15.81 \pm 1.02$ & 723 & $50(6.9)$ & 317 & $24(7.6)$ & 406 & $26(6.4)$ \\
\hline $\begin{array}{l}\text { Ghayeghran and } \\
\text { Fathe (29) }\end{array}$ & 2004 & Rasht & $15.3 \pm 1.11$ & 1965 & $174(8.8)$ & 1075 & $68(6.3)$ & 890 & $106(11.9)$ \\
\hline Mirzaei (30) & 2004 & Shahrekord & $14-20$ & & & & & 550 & $73(13.3)$ \\
\hline
\end{tabular}

${ }^{\mathrm{a}}$ Values are presented as No (\%).

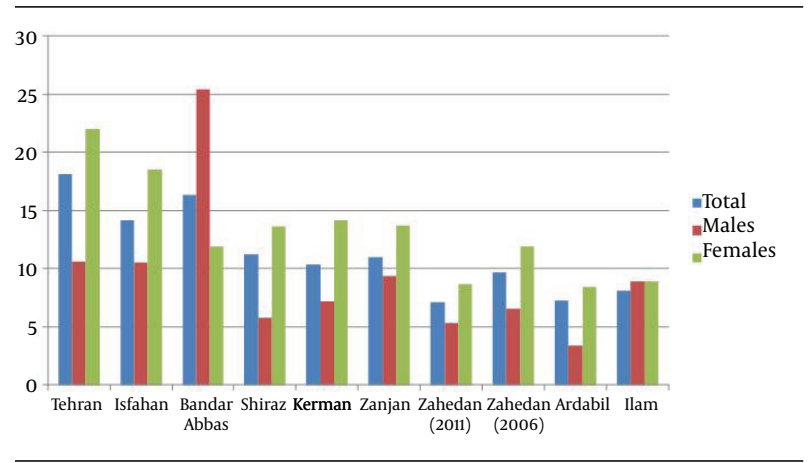

Figure 1. Prevalence of Migraine in Adults

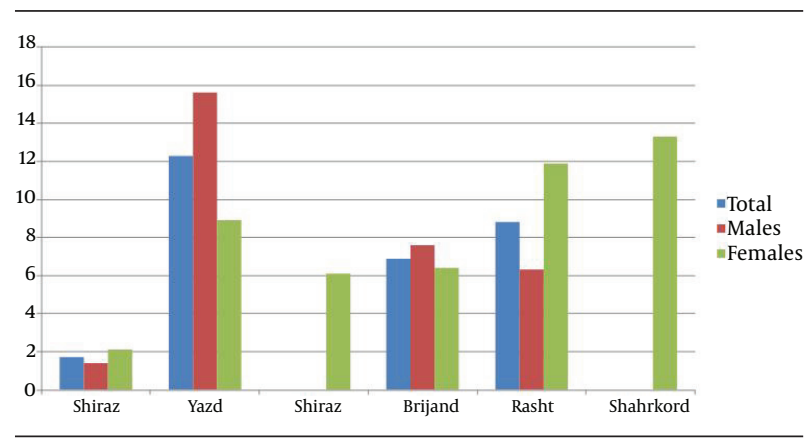

Figure 2. Prevalence of Migraine in Children and Adolescences

In most evaluated studies, migraine was the most prevalent in middle-age individuals and women. The prevalence of migraine in adults varies from $7.14 \%$ to $18.11 \%$, and the maximum and minimum prevalence was reported from Tehran (capital of Iran) (15) and Zahedan (southeast of Iran) (23), respectively. In children and adolescences, the prevalence varied from $1.7 \%$ to $12.3 \%$, and the lowest and the highest prevalence were from Shiraz (southwest of Iran) (16) and Yazd (southeast of Isfahan) (27), respectively.

\section{Conclusions}

In this study, we found a high prevalence of migraine in evaluated studies. The prevalence of migraine in adults varied from $7.14 \%$ to $18.11 \%$ while in children and adoles- cences it varied from $1.7 \%$ to $12.3 \%$. Consistent with our results, a review of all epidemiological studies in European countries indicated that the prevalence of migraine among adults ranged $8 \%$ to $17.6 \%$, while among children and adolescence it ranged 5.2\% to 9.1\% (31). In another systematic review and meta-analysis, it was shown that $5.6 \%$ to $8 \%$ of children and adolescence had migraine over periods ranging from three months to a lifetime (32). There are many factors that may be the reason for the high prevalence of migraine in this study compared to the two mentioned review studies. A large number of studies proved the effect of dietary factors including consumption of coffee, monosodium and tyramine-containing foods and high fat diet on incidence or exacerbation of migraine; these dietary products are high in Iranian diets (33). In addition, nutritional deficiencies such as vitamin $\mathrm{D}$ in the Iranian population may be another reason for high prevalence of migraine in Iran (14). Furthermore, high prevalence of obesity $(9-11,34,35)$, psychological difficulties (36), low educational level and marital status (37) are other factors which can contributed to the high prevalence of migraine in Iran.

Our results showed that among adults, the maximum prevalence was reported from Tehran and the minimum from Zahedan. In children and adolescence, the lowest prevalence was found in Shiraz and the highest prevalence in Yazd. The prevalence differences between cities may be due to the combination of genetic mutations and environmental factors including dietary patterns, lifestyle, culture, socio-economic factors and education level.

Our results showed that migraine was the most prevalent in middle-age individuals and women. In a large population-based study in Latin American countries, migraine predominantly affected women aged 30 to 50 years (38). In addition, one meta-analysis showed that migraine prevalence increases from adolescence to around the age of 40 years and higher prevalence of migraine was found in females when compared to males (31). One of the main reasons which can explain the high prevalence of migraine among females is female sex hormones that affect the sense of pain (39). 
Despite wide differences in the prevalence of migraine in different epidemiological studies among adults or children and adolescence in Iran, a clear and reliable estimate of the problem is difficult since we have no data on the prevalence of migraine in other provinces of Iran. Above all, all evaluated studies were done in urban areas, and no data is available for the prevalence of migraine in rural areas. Therefore, we cannot have an overall conclusion about the prevalence of migraine in Iran. Thus, further studies especially large population-based studies, which consider all Iranian provinces, are needed to find the real prevalence of migraine in Iran.

Based on the current findings, the prevalence of migraine in evaluated studies was high. Therefore, it is recommended for public health authorities to detect the reasons for the high prevalence of this disease and present appropriate strategies to prevent this disorder.

\section{Acknowledgements}

This article was supported by the Isfahan University of Medical Sciences, Isfahan, IR Iran. Hereby, we appreciate the Research Deputy Vice-chancellor for research affairs of the Isfahan University of Medical Sciences for their technical support.

\section{Authors' Contributions}

Omid Sadeghi, Saed Ghasem Saiedi and Morteza Nasiri contributed equally to this work and performed the literature search and wrote the first draft. Omid Sadeghi and Morteza Nasiri provided expert opinion and reviewed the paper.

\section{Funding/Support}

This article was supported by the Isfahan University of Medical Sciences, Isfahan, IR Iran.

\section{References}

1. Schurks M, Buring JE, Kurth T. Migraine, migraine features, and cardiovascular disease. Headache. 2010;50(6):1031-40.

2. Miller S, Matharu MS. Migraine is underdiagnosed and undertreated. Practitioner. 2014;258(1774):19-24.

3. Unalp A, Dirik E, Kurul S. Prevalence and clinical findings of migraine and tension-type headache in adolescents. Pediatr Int 2007;49(6):943-9.

4. Lateef TM, Cui L, Nelson KB, Nakamura EF, Merikangas KR. Physical comorbidity of migraine and other headaches in US adolescents. J Pediatr. 2012;161(2):308-13 e1.

5. Lipton RB, Pavlovic JM, Haut SR, Grosberg BM, Buse DC. Methodological issues in studying trigger factors and premonitory features of migraine. Headache. 2014;54(10):1661-9.

6. Petrusic I, Pavlovski V, Vucinic D, Jancic J. Features of migraine aura in teenagers. J Headache Pain. 2014;15:87.

7. Headache Classification Subcommittee of the International Headache S. The International Classification of Headache Disorders: 2nd edition. Cephalalgia. 2004;24 Suppl 1:9-160.

8. DeLange JM, Cutrer FM. Our evolving understanding of migraine with aura. Curr Pain Headache Rep. 2014;18(10):453.

9. Scher AI, Eiriksdottir G, Garcia M, Feit P, Smith AV, Harris TB, et al. Lack of association between the MTHFR C677T variant and mi- graine with aura in an older population: could selective survival play a role? Cephalalgia. 2013;33(5):308-15.

10. Ghosh J, Pradhan S, Mittal B. Multilocus analysis of hormonal, neurotransmitter, inflammatory pathways and genome-wide associated variants in migraine susceptibility. Eur $J$ Neurol. 2014;21(7):1011-20.

11. Recober A, Peterlin BL. Migraine and obesity: moving beyond BMI. Future Neurol. 2014;9(1):37-40.

12. Victor TW, Hu X, Campbell JC, Buse DC, Lipton RB. Migraine prevalence by age and sex in the United States: a life-span study. Cephalalgia. 2010;30(9):1065-72.

13. Steiner TJ, Paemeleire K, Jensen R, Valade D, Savi L, Lainez MJ, et al. European principles of management of common headache disorders in primary care. J Headache Pain. 2007;8 Suppl 1:S3-47.

14. Wang SJ. Epidemiology of migraine and other types of headache in Asia. Curr Neurol Neurosci Rep. 2003;3(2):104-8.

15. Shahbeigi S, Fereshtehnejad SM, Mohammadi N, Golmakani MM Tadayyon S, Jalilzadeh G, et al. Epidemiology of headaches in Tehran urban area: a population-based cross-sectional study in district 8, year 2010. Neurol Sci. 2013;34(7):1157-66.

16. Ayatollahi SM, Khosravi A. Prevalence of migraine and tensiontype headache in primary-school children in Shiraz.East Mediterr Health J. 2006;12(6):809-17.

17. Ayatollahi SMT, Sahebi L, Borhani Haghighi A. Epidemiologic and clinical characteristics of migraine and tension-type headaches among hospitals staffs of Shiraz (Iran). Acta Medica Iranica. 2009;47(2):115-20

18. Bahrampour A, Mobashe M. The evaluation of Migraine prevalence and associated demographic factors among government employees' of Kerman city. Journal of Kerman University of Medical Sciences. 1998;5(2):84-91.

19. Ghorbani A, Abtahi SM, Fereidan-Esfahani M, Abtahi SH, Shemshaki H, Akbari M, et al. Prevalence and clinical characteristics of headache among medical students, Isfahan, Iran.J Res Med Sci. 2013;18(Suppl 1):S24-7.

20. Yazdanparast M, Abrishamizadeh AA. Prevalence of and Factors Associated withMigraine inMedical Students at BandarAbbas, Southern Iran, in 2012. Electronic physician. 2013;5(3):679-84.

21. Yusefy M. Prevalence of migraine among students of Zanjan University of Medical Science. J Zanjan Uni of Med Sci. 1999;8(3031):18-24.

22. Shahraki M, Heydari SB, Moghtaderi A, Mirshekari H. The study of prevalence of migraine among teachers at zahedan, Iran. Tabib-eShargh. 2006;8(2):137-42.

23. Shahrakai MR, Mirshekari H, Ghanbari AT, Shahraki AR, Shahraki E. Prevalence of Migraine Among Medical Students in Zahedan Faculty of Medicine (Southeast of Iran). Basic and clinical Neuroscience. 2011;2(2):20-5.

24. Hashemilar M, AMINI SN, SAVADI OD, Yosefian M. The prevalence of migraine among students of Ardabil University of medical sciences. JAUMS. 2004;3(11):64-70.

25. Modara FR. Prevalence of tension and migraine headaches among the students of Ilam Medical University. JIUM . 2008;15(4):13-21.

26. Ayatollahi SM, Moradi F, Ayatollahi SA. Prevalences of migraine and tension-type headache in adolescent girls of Shiraz (southern Iran). Headache. 2002;42(4):287-90.

27. Fallahzadeh H, Alihaydari M. Prevalence of migraine and tension-type headache among school children in Yazd, Iran.JPediatr Neurosci. 2011;6(2):106-9.

28. Khazaie T, Dehghani Firoozabadi M, Sharifzadeh GR. Prevalence of migraine and its relationship to educational performance in adolescents of Brijand city (2010). Journal of Birjand University of Medical Sciences. 2011;18(2):94-101.

29. Ghayeghran AR, Fathe SSH. Survey on prevalence of migraine in highschool students of rasht-city. Journal of Guilan University of Medical Sciences. 2004;13(50):22-6.

30. Mirzaei G. A review of cammon migraine in girls high school and related fall in education in Shahrekord region. Journal of Shahrekord University of Medical Sciences. 2004;5(4):55-62.

31. Stovner LJ, Andree C. Prevalence of headache in Europe: a review for the Eurolight project. J Headache Pain. 2010;11(4):289-99.

32. Abu-Arafeh I, Razak S, Sivaraman B, Graham C. Prevalence of 


\section{Sadeghi $O$ et al.}

headache and migraine in children and adolescents: a systematic review of population-based studies. Dev Med Child Neurol. 2010;52(12):1088-97.

33. Finkel AG, Yerry JA, Mann JD. Dietary considerations in migraine management: does a consistent diet improve migraine? Curr Pain Headache Rep. 2013;17(11):373.

34. Rossoni de Oliveira V, Camboim Rockett F, Castro K, da Silveira Perla A, Chaves ML, Schweigert Perry ID. Body mass index, abdominal obesity, body fat and migraine features in women. Nutr Hosp. 2013;28(4):1115-20.

35. Yu S, Liu R, Yang X, Zhao G, Qiao X, Feng J, et al. Body mass index and migraine: a survey of the Chinese adult population. J Headache Pain. 2012;13(7):531-6.
36. Abbate-Daga G, Fassino S, Lo Giudice R, Rainero I, Gramaglia C, Marech L, et al. Anger, depression and personality dimensions in patients with migraine without aura. Psychother Psychosom. 2007;76(2):122-8.

37. Phillips J, Longridge N, Mallinson A, Robinson G. Reply to: "Response to: Migraine and vertigo: a marriage of convenience?". Headache. 2011;51(7):1173-4.

38. Morillo LE, Alarcon F, Aranaga N, Aulet S, Chapman E, Conterno $\mathrm{L}$, et al. Prevalence of migraine in Latin America. Headache. 2005;45(2):106-17.

39. Sumanen MP, Ojanlatva A, Rantala A, Sillanmaki LH, Mattila KJ Gender differences in sex life issues - a population-based study of migraine sufferers. BMC Fam Pract. 2008;9:19. 